\title{
Is a Ruminative Thinking Style Related to Obsessive-Compulsive Symptom Severity Beyond Its Associations with Depressive and Anxiety Symptom Severity?
}

\author{
Carlotta V. Heinzel ${ }^{1}$. Martin Kollárik ${ }^{1}$ - Marcel Miché ${ }^{1} \cdot$ Annika Clamor $^{2}$. \\ Andrea Ertle ${ }^{3} \cdot$ Roselind Lieb ${ }^{1} \cdot$ Karina Wahl ${ }^{1}$
}

Accepted: 2 June 2021/ Published online: 30 June 2021

(C) The Author(s) 2021

\begin{abstract}
Previous studies suggest that a ruminative thinking style (RTS) is positively associated with the severity of obsessive-compulsive symptoms and might be involved in the maintenance of obsessive-compulsive disorder (OCD). We sought to replicate this association in a sample of individuals with OCD, controlling for depressive and anxiety symptom severity, and to extend previous studies by including an interview measure of obsessive-compulsive symptom severity. A sample of 140 individuals diagnosed with OCD participated in a cross-sectional observational study. Participants completed questionnaire measures of an RTS as well as obsessive-compulsive, depressive, and anxiety symptom severity. Obsessive-compulsive symptom severity was additionally assessed with an interview. When statistically controlling for depressive and anxiety symptom severity, an RTS continued to predict the questionnaire, but not the interview measure of obsessive-compulsive symptom severity. We discuss possible explanations for these mixed findings, emphasizing the unique aspects of each measure, and consider implications for further research on OCD.
\end{abstract}

Keywords Rumination (cognitive process) - Obsessive-compulsive disorder . Depression (emotion) $\cdot$ Anxiety $\cdot$ Patients

\section{Introduction}

Obsessive-compulsive disorder (OCD) is a severely impairing mental disorder with a lifetime prevalence of approximately 1-3\% (American Psychiatric Association, 2013; Fontenelle et al., 2006; Guzick et al., 2017; Lieb et al., 2019). It is characterized by

Karina Wahl

karina.wahl@unibas.ch

Extended author information available on the last page of the article 
recurrent intrusive and unwanted thoughts (obsessions) that are typically followed by mental acts or observable behaviors (compulsions) aimed at reducing the distress or perceived danger associated with these obsessions (American Psychiatric Association, 2013). Previous studies suggest that a ruminative thinking style (RTS) is positively associated with obsessive-compulsive (OC) symptom severity (e.g., Dar \& Iqbal, 2015; Wahl et al., 2011). An RTS has been defined as "a mode of responding to distress that involves repetitively and passively focusing on symptoms of distress and on the possible causes and consequences of these symptoms" (Nolen-Hoeksema et al., 2008 , p. 400). This concept originated from the literature on depression and the associations between an RTS and symptoms of depression, and many other mental disorders have been investigated extensively (for overviews, see Ehring \& Watkins, 2008; Nolen-Hoeksema et al., 2008).

Multiple studies have supported positive associations of an RTS with OC symptom severity. Between-group comparisons have shown a stronger self-reported RTS in individuals diagnosed with OCD compared to those diagnosed with a generalized anxiety disorder (Dar \& Iqbal, 2015; however, note that Armstrong et al., 2011 did not find such differences) and those without any diagnosis of an Axis I disorder from the Diagnostic and Statistical Manual of Mental Disorders (4th ed.; DSM-IV; American Psychiatric Association, 1994; Armstrong et al., 2011; Koch \& Exner, 2015). Furthermore, an RTS has been positively associated with OC symptom severity in students and the general population (Grisham \& Williams, 2009; Jungmann et al., 2016; Shaw et al., 2017; Wahl et al., 2011) as well as in heterogeneous clinical samples of individuals diagnosed with a variety of mental disorders (e.g., anxiety disorders, depressive disorders, and OCD; Dar \& Iqbal, 2015; Raines et al., 2017). Recently, Wei et al. (2020) demonstrated this association in a treatment-receiving sample of adolescents and young adults diagnosed with OCD, although these results should be interpreted with caution due to the study's use of an unvalidated two-item measure of an RTS. Two recent experimental studies have shown an RTS to maintain the urge to neutralize unwanted intrusive thoughts (a subclinical analog to the urge to perform compulsions in response to unwanted intrusions; Kollárik et al., 2020; Wahl et al., 2019). These experimental studies suggest that an RTS might not only be associated with OC symptom severity but might also contribute to its maintenance. Although this literature provides strong support for a positive association of an RTS and OC symptom severity, no study has so far investigated this association in a sample consisting exclusively of individuals with a diagnosis of OCD using a well-established RTS measure. Replicating these results in such a sample would further strengthen the evidence for this association.

Several cognitive mechanisms that might explain a possible functional relationship between an RTS and obsessive thoughts and compulsions have been proposed. For instance, an RTS may facilitate dysfunctional interpretations of intrusive thoughts (Raines et al., 2017; Wahl et al., 2019) that are seen as central to the development and maintenance of OC symptoms in current models of OCD (e.g., Rachman, 1998). However, the high comorbidity of OCD with depression and anxiety disorders (Baer et al., 2017; Lieb et al., 2019) suggests an alternative explanation for the relationship between an RTS and the severity of OC symptoms: It may be due to both constructs' associations with depressive and anxiety symptom severity. This explanation is supported by both depressive and anxiety symptom severity showing medium to large 
positive associations with OC symptom severity (e.g., Abramowitz \& Deacon, 2006; Clark et al., 2005; Goodman et al., 1989a; Tellawi et al., 2016) as well as with an RTS (e.g., Merino et al., 2014; Merino et al., 2016; Nolen-Hoeksema, 2000; Rogers et al., 2019; Treynor et al., 2003; Yang et al., 2014).

If the association between an RTS and OC symptom severity can be accounted for by depressive and anxiety symptom severity, then the association should disappear when these confounders are statistically controlled for. So far, only a few studies have statistically controlled for these variables. Wahl et al. (2011) and Raines et al. (2017) conducted studies on samples of students and individuals diagnosed with various mental disorders, respectively. In these studies, an RTS was positively associated with the severity of some, but not all, OC symptoms when controlling for depressive symptom severity or negative affect. Only two studies have reported associations between an RTS and OC symptom severity while controlling for both depressive and anxiety symptom severity at the same time. Grisham and Williams (2009) demonstrated a moderate positive relationship of an RTS with OC symptom severity when controlling for depressive and anxiety symptom severity in a student sample. Shaw et al. (2017) conducted an online study with a sample of individuals who had mostly (83\%) not reported previous diagnoses of mental disorders. In their study, only one of the OC symptom subscales, responsibility for harm, showed a small positive association with an RTS after controlling for depressive and anxiety symptom severity. The associations of an RTS with the other three subscales (contamination, symmetry, and unacceptable thoughts) as well as total OC symptom severity were not significant after controlling for these possible confounders. To summarize, although there is conflicting evidence, previous studies have demonstrated associations of an RTS with some, but not all, aspects of OC symptom severity when controlling for depressive and anxiety symptom severity. However, none of the previous studies investigated these associations in a sample of individuals diagnosed with OCD. If they can be replicated with individuals diagnosed with OCD, this may help inform cognitive-behavioral models and optimal treatment of OCD. For example, an RTS may emerge as an additional maladaptive response to OC symptoms that maintains these symptoms in the long term (as suggested by Kollárik et al., 2020; Wahl et al., 2019, in press). If this is the case, therapists and individuals with OCD could work collaboratively on identifying an RTS as a potentially maladaptive response to OC symptoms as part of the case conceptualization in cognitive-behavioral therapy, and this assumption would be tested in later behavioral experiments. Moreover, if an RTS maintains OC symptoms, then eventually cognitive-behavioral therapy could be supplemented by specific interventions that target an RTS, for example, an adapted version of rumination-focused cognitivebehavioral therapy (RFCBT; Watkins, 2016), mindfulness-based cognitive therapy (Külz et al., 2019), or interpretive bias modification (Hirsch et al., 2020).

Additionally, none of the previous studies used the Yale-Brown Obsessive-Compulsive Scale (Y-BOCS; Goodman et al., 1989b). The Y-BOCS is an interview measure of OC symptom severity that is generally considered the gold standard (e.g., Grabill et al., 2008). Compared to the Obsessive-Compulsive Inventory-Revised (OCI-R; Foa et al., 2002; used by Grisham \& Williams, 2009), which focuses on the distress associated with OC symptoms, the Y-BOCS also measures additional aspects of OC symptom severity, such as interference from or control over OC symptoms (Abramowitz \& Deacon, 2006). Furthermore, when an RTS is assessed with a self- 
report questionnaire, using an interview measure of OC symptom severity has the additional advantage of reducing the possibility that associations with an RTS are due to common method variance (e.g., Podsakoff et al., 2003).

This study aimed to investigate the association of an RTS with OC symptom severity with and without controlling for depressive and anxiety symptom severity in a sample of individuals with OCD. We extended previous studies by using an interview measure (Y-BOCS) in addition to a questionnaire (OCI-R) to assess OC symptom severity. First, we hypothesized that an RTS would be positively associated with both (1a) a questionnaire and (1b) an interview measure of OC symptom severity. Second, we hypothesized that an RTS would remain positively associated with (2a) the questionnaire and (2b) the interview measure of OC symptom severity after depressive and anxiety symptom severity were accounted for. Additionally, we used exploratory analyses to investigate the associations of an RTS with the subscales of both OC symptom severity measures, with and without controlling for depressive and anxiety symptom severity.

\section{Materials and Methods}

\section{Participants and Procedure}

All participants were recruited and tested in six inpatient and outpatient clinics in Germany as part of the three studies investigating psychological mechanisms in OCD. Therefore, three slightly different subsamples were aggregated in this study. In total, data from $N=140$ individuals diagnosed with OCD were included. Criteria for all diagnoses in this study were based on the DSM-IV (American Psychiatric Association, 1994). Exclusion criteria for all participants were current substance abuse or dependence, current psychotic symptoms, or current suicidal intent. Additionally, in Subsample 1, but not the other subsamples, individuals with diagnoses of major depressive disorder or generalized anxiety disorder within the past 12 months were excluded from study participation.

All participants were tested within the first 2 weeks of treatment. Subsamples 1 and 2 completed identical measures of all variables. Subsample 3 also completed these measures, but no interview measure of OC symptom severity was administered. Experienced clinicians or trained graduate students assessed the participants' OCD and comorbid diagnoses using the Structured Clinical Interview for DSM-IV Axis I Disorders (SCID-I; Wittchen et al., 1997). During the same session, they measured OC symptom severity using the Y-BOCS (Goodman et al., 1989b). Furthermore, each participant completed the questionnaires detailed in the Materials section during the same session. All participants gave their written informed consent. The participants' demographic and clinical characteristics are presented in Table 1. The three Subsamples did not differ with regard to age, $F(2,134)=0.33, p=.72$, or gender, $\chi^{2}(2)=0.86$, $p=.65$. Because of the different exclusion criteria for Subsample 1 compared to the other two subsamples, we analyzed current comorbidities of anxiety and major depressive disorders. The subsamples did not differ regarding their levels of current anxiety disorder comorbidities, $\chi^{2}(2)=4.28, p=.12$, but they differed with regard to their concurrent comorbidities with major depressive disorder, $\chi^{2}(2)=24.20, p<.001$. 


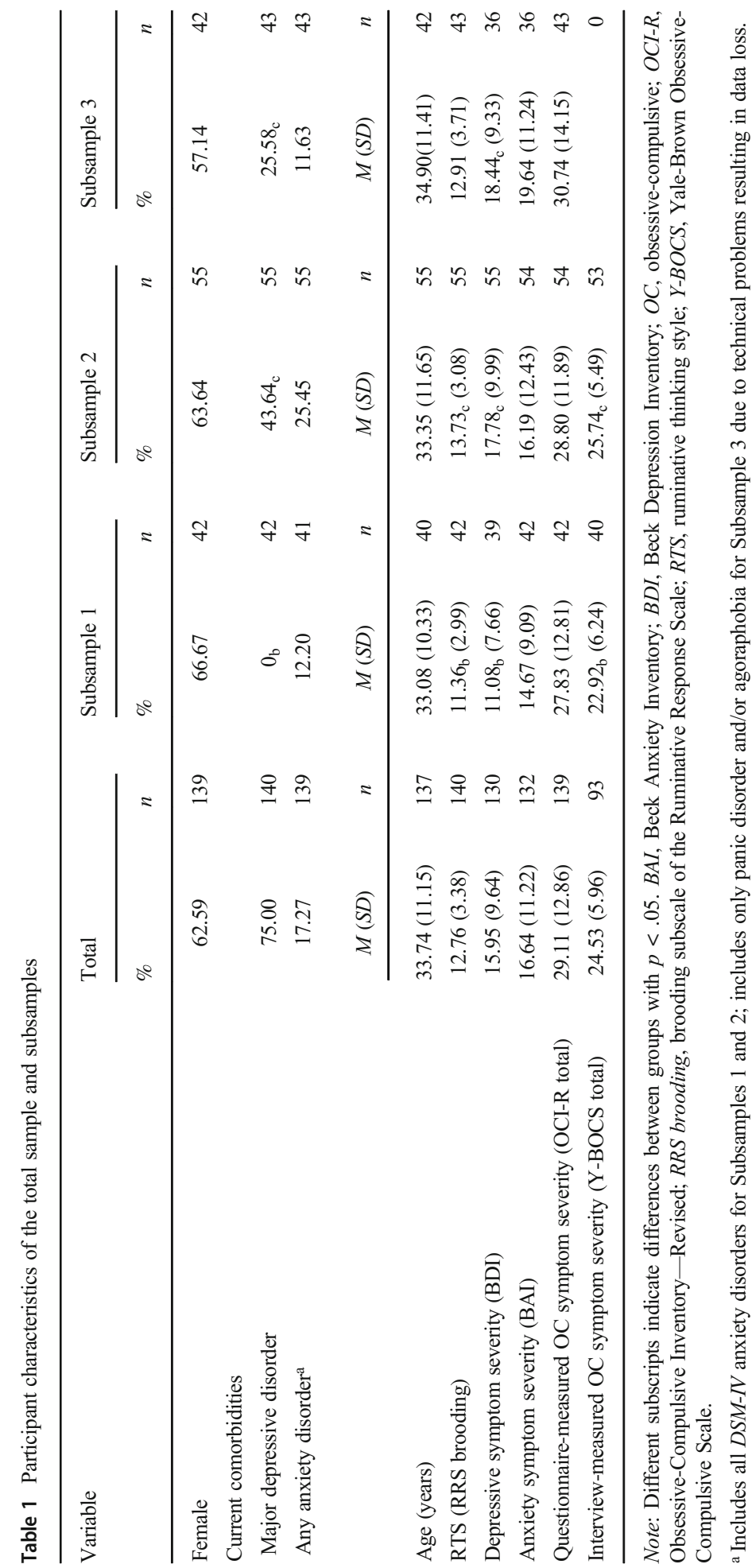


Regarding RTS, depressive, anxiety, and OC symptom severity, we tested for differences between the subsamples using analyses of variance and Gabriel's post hoc tests or, where their assumptions were violated, Kruskal-Wallis and GamesHowell tests. The subsamples did not differ with regard to the questionnaire measures of OC symptom severity or anxiety symptom severity. However, they showed different levels to which they adopted an RTS and different levels of depressive symptom severity, and they differed in the interview measure of OC symptom severity.

\section{Materials}

\section{RTS Assessment}

To assess the participants' RTS, we employed the Ruminative Response Scale (RRS; Nolen-Hoeksema \& Morrow, 1991; German version by Huffziger \& Kühner, 2012). The RRS is a questionnaire measuring typical ruminative responses to dysphoric mood with three subscales (Treynor et al., 2003). We used only the brooding subscale (Treynor et al., 2003) as a measure of an RTS that is not confounded with the assessment of depressive symptoms. The brooding subscale consists of five items and has shown adequate psychometric properties in both its English and German versions (Huffziger \& Kühner, 2012; Treynor et al., 2003). In our study, the internal consistency of the brooding subscale was acceptable, with Cronbach's $\alpha=.73$.

\section{Assessment of OC Symptom Severity}

We assessed OC symptom severity in two ways. First, we employed the ObsessiveCompulsive Inventory_-Revised (OCI-R; Foa et al., 2002; German version by Gönner et al., 2008), an 18-item questionnaire measuring OC symptom severity during the past month. OC symptom severity is operationalized by the distress caused by OC symptoms (Foa et al., 2002). The questionnaire comprises six subscales: washing, checking, ordering, obsessing, hoarding, and neutralizing. The OCI-R has high reliability and good convergent validity (Foa et al., 2002; Gönner et al., 2008). Although the strength of its associations with measures of depressive symptom severity varies, its discriminant validity is generally acceptable (Abramowitz \& Deacon, 2006; Foa et al., 2002; Gönner et al., 2008). In the present study, the OCI-R total score had high internal consistency, with Cronbach's $\alpha=.82$.

Second, we used the Yale-Brown Obsessive-Compulsive Scale (Y-BOCS; Goodman et al., 1989b; German version by Hand \& Büttner-Westphal, 1991), which is a semistructured interview assessing the severity of OC symptoms during the past week. The Y-BOCS comprises two subscales - obsessions and compulsions - with five items each. In this study, a total score of all 10 items was used to measure obsession and compulsion severity in addition to the two subscales. The Y-BOCS has high reliability (Goodman et al., 1989b; Jacobsen et al., 2003; Woody et al., 1995) and good convergent validity (Abramowitz et al., 2010; Gönner et al., 2008). However, it can be criticized for its high correlations with measures of depression (Clark et al., 2005; Goodman et al., 1989a; Rees et al., 2014). In contrast to the operationalization in the OCI-R, OC symptom severity is operationalized more globally in the Y-BOCS, which 
measures not only the distress associated with but also the interference from, resistance against, control over, and time spent on obsessions and compulsions (Abramowitz \& Deacon, 2006).

\section{Assessment of Depressive and Anxiety Symptom Severity}

We assessed depressive symptom severity during the past week using the Beck Depression Inventory (BDI; Beck et al., 1961; German version by Hautzinger et al., 1995), which consists of 21 items. Its high reliability and validity have been shown in numerous studies (Beck et al., 1988b; Hautzinger et al., 1995). In this study, the BDI showed excellent internal consistency, with Cronbach's $\alpha=.90$.

Anxiety symptom severity during the past week was measured using the Beck Anxiety Inventory (BAI; Beck et al., 1988a; German version by Margraf \& Ehlers, 2007), a 21-item questionnaire. The BAI has high reliability and good validity (e.g., Beck et al., 1988a; Margraf \& Ehlers, 2007). In the present study, its internal consistency was excellent, with Cronbach's $\alpha=.91$.

\section{Analyses}

All analyses were conducted using IBM SPSS Statistics, Version 26.0, and a significance level of $\alpha=5 \%$. We examined the distribution of the main variables using visual inspection of histograms and Q-Q plots as well as tests of normality (KolmogorovSmirnov and Shapiro-Wilk). Because the values for the questionnaire measures of OC, depressive, and anxiety symptom severity were nonnormally distributed (see the online supplement for the variables' skew and kurtosis statistics), we applied a square-root transformation to these three variables before regression analyses. After we applied these transformations, the assumptions for all analyses were met. Because the three subsamples differed with regard to RTS, depressive symptom severity, and the interview measure of OC symptom severity, we controlled for subsamples in our analyses, using dummy coding where applicable. We investigated Hypothesis $1 \mathrm{a}$ and $\mathrm{b}$ by conducting linear regression analyses with an RTS predicting each measure of OC symptom severity and controlling for subsamples. For Hypothesis $2 \mathrm{a}$ and $\mathrm{b}$, we extended the regression models to include the predictors depressive and anxiety symptom severity. For comparison with previous studies, we report partial correlation coefficients ( $p r s$ ) for the association between each predictor and the outcome in addition to regression coefficients in the regression models. For the exploratory analyses, we repeated the regression models from our Hypotheses 1 and 2 with the subscales of each OC symptom severity measure (except for OCI-R hoarding, because hoarding is classified as a separate disorder in the DSM-5; American Psychiatric Association, 2013) as outcomes. Although we also controlled for subsamples in these analyses, for brevity, we do not report statistics for these predictors in the exploratory analyses. As additional information, we report zero-order correlations between the main variables in the online supplement. We checked for univariate outliers using boxplots and scatterplots and for multivariate outliers using Mahalanobis distance (cutoffs based on Kline, 2016). Two multivariate outliers emerged and closer examination of the participants showed discrepancies on the Y-BOCS, but otherwise the participants' characteristics seemed to fit the target population. We excluded these two participants 
from all analyses using the Y-BOCS subscales and total scores, and when we repeated the outlier analyses, no multivariate outliers emerged.

\section{Results}

The RTS showed positive associations with both the questionnaire and the interview measure of OC symptom severity when only subsamples were controlled for (see Model 1 in Table 2). When we additionally controlled for depressive and anxiety symptom severity (see Model 2 in Table 2), the RTS continued to predict the questionnaire-based measure of OC symptom severity. However, the association between the RTS and the interview measure of OC symptom severity was not retained after depressive and anxiety symptom severity were controlled for.

Tables 3 and 4 present exploratory analyses for the associations of the RTS with OCI-R and Y-BOCS subscales. Regarding the OCI-R subscales, exploratory analyses showed that the highest association with an RTS, controlling for depressive and anxiety symptom severity, emerged for ordering (Model 2 in Table 3). The next highest effect size, controlling for depressive and anxiety symptom severity, emerged for OCI-R mental neutralizing. Model 2 for OCI-R obsessing showed a similar effect size to OCI$\mathrm{R}$ mental neutralizing but did not quite reach significance. Regarding the Y-BOCS subscales, exploratory analyses demonstrated that neither the obsessions nor the compulsions subscale remained associated with an RTS when depressive and anxiety symptom severity were controlled for (Model 2 in Table 4).

\section{Discussion}

The present study investigated the association between an RTS and OC symptom severity, controlling for depressive and anxiety symptom severity, in individuals diagnosed with OCD. Before depressive and anxiety symptom severity were controlled for, the RTS were positively associated with two different measures of OC symptom severity (OCI-R and Y-BOCS, Foa et al., 2002; Goodman et al., 1989b). These findings replicate those reported in previous studies (Dar \& Iqbal, 2015; Grisham \& Williams, 2009; Jungmann et al., 2016; Raines et al., 2017; Shaw et al., 2017; Wahl et al., 2011; Wei et al., 2020) in a sample consisting exclusively of individuals diagnosed with OCD. The effect sizes in our study tended to be lower than those reported by previous studies using similar measures (for the questionnaire measure: $p r$ $=.45$, cf. $r=.58$ in Grisham \& Williams, 2009; for the interview measure: $\beta=.28$, cf. $\beta=.55$ in Wei et al., 2020). Our results provide further evidence on the association between an RTS and OC symptoms in the population that is most relevant for potential conceptual and clinical implications.

When statistically controlling for depressive and anxiety symptom severity, the RTS remained positively associated with the questionnaire-based measure of OC symptom severity, supporting Hypothesis 2a. The results for this measure replicate those of previous studies on students and individuals diagnosed with various mental disorders (Grisham \& Williams, 2009; Raines et al., 2017; Wahl et al., 2011) in individuals diagnosed with OCD. The effect size in our study $(p r=.25)$ is in between those of 


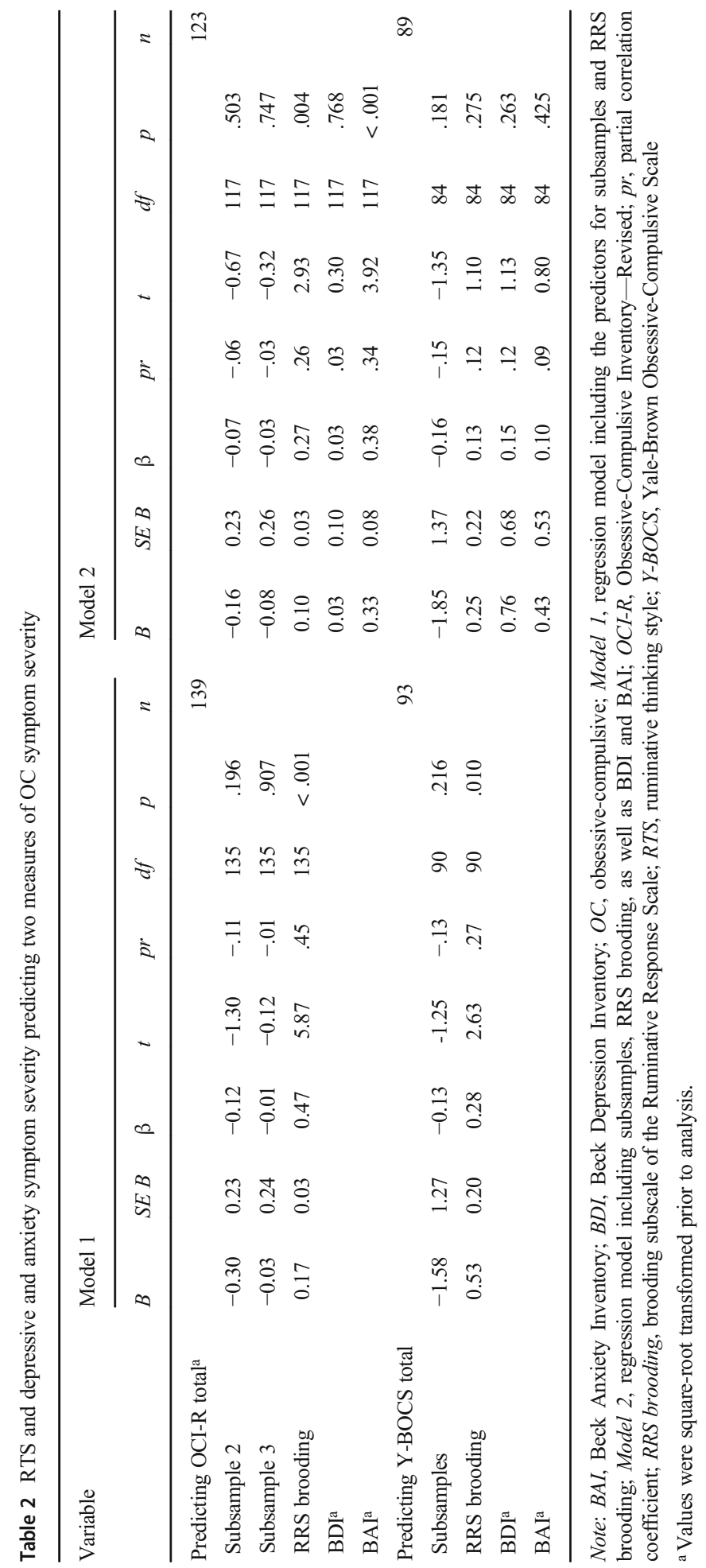


Table 3 Exploratory analyses of the RTS and depressive and anxiety symptom severity predicting the OC symptom severity questionnaire measure subscales, controlling for subsamples

\begin{tabular}{|c|c|c|c|c|c|c|c|c|c|c|}
\hline \multirow[t]{2}{*}{ Variable } & \multicolumn{5}{|c|}{ Model 1} & \multicolumn{5}{|c|}{ Model 2} \\
\hline & $B$ & $S E B$ & $\beta$ & $p r$ & $p$ & $B$ & $S E B$ & $\beta$ & $p r$ & $p$ \\
\hline \multicolumn{11}{|c|}{ Predicting OCI-R washing ${ }^{\mathrm{a}}$} \\
\hline RRS brooding & 0.03 & 0.02 & 0.09 & .09 & .298 & -0.01 & 0.03 & -0.05 & -.04 & .638 \\
\hline $\mathrm{BDI}^{\mathrm{a}}$ & & & & & & 0.16 & 0.09 & 0.20 & .16 & .085 \\
\hline $\mathrm{BAI}^{\mathrm{a}}$ & & & & & & 0.01 & 0.08 & 0.01 & .01 & .914 \\
\hline \multicolumn{11}{|c|}{ Predicting OCI-R checking } \\
\hline RRS brooding & 0.32 & 0.10 & 0.26 & .25 & .003 & 0.21 & 0.13 & 0.17 & .15 & .111 \\
\hline $\mathrm{BDI}^{\mathrm{a}}$ & & & & & & 0.08 & 0.42 & 0.02 & .02 & .843 \\
\hline $\mathrm{BAI}^{\mathrm{a}}$ & & & & & & 0.38 & 0.34 & 0.13 & .10 & .264 \\
\hline \multicolumn{11}{|c|}{ Predicting OCI-R ordering ${ }^{\mathrm{a}}$} \\
\hline RRS brooding & 0.08 & 0.02 & 0.40 & .38 & $<.001$ & 0.06 & 0.02 & 0.27 & .25 & .006 \\
\hline $\mathrm{BDI}^{\mathrm{a}}$ & & & & & & 0.001 & 0.07 & 0.001 & .001 & .990 \\
\hline $\mathrm{BAI}^{\mathrm{a}}$ & & & & & & 0.15 & 0.05 & 0.29 & .25 & .006 \\
\hline \multicolumn{11}{|c|}{ Predicting OCI-R obsessing ${ }^{\mathrm{b}}$} \\
\hline RRS brooding & 0.08 & 0.02 & 0.34 & .32 & $<.001$ & 0.04 & 0.02 & 0.18 & .18 & .053 \\
\hline $\mathrm{BDI}^{\mathrm{a}}$ & & & & & & -0.06 & 0.07 & -0.09 & -.08 & .368 \\
\hline $\mathrm{BAI}^{\mathrm{a}}$ & & & & & & 0.28 & 0.06 & 0.49 & .42 & $<.001$ \\
\hline \multicolumn{11}{|c|}{ Predicting OCI-R mental neutralizing ${ }^{\mathrm{a}}$} \\
\hline RRS brooding & 0.07 & 0.02 & 0.27 & .26 & .002 & 0.05 & 0.03 & 0.21 & .18 & .048 \\
\hline $\mathrm{BDI}^{\mathrm{a}}$ & & & & & & -0.03 & 0.08 & -0.05 & -.04 & .679 \\
\hline $\mathrm{BAI}^{\mathrm{a}}$ & & & & & & 0.12 & 0.07 & 0.20 & .16 & .072 \\
\hline
\end{tabular}

Note: $n=140$ for Model 1 (regression model including subsamples and RRS brooding) and $n=124$ for Model 2 (regression model including subsamples, RRS brooding, BDI, and BAI), with one participant's values missing for both models using the ordering subscale. BAI, Beck Anxiety Inventory; BDI, Beck Depression Inventory; $O C$, obsessive-compulsive; $O C I-R$, Obsessive-Compulsive Inventory-Revised; $p r$, partial correlation coefficient; RRS brooding, brooding subscale of the Ruminative Response Scale; RTS, ruminative thinking style.

a Values were square-root transformed prior to analysis.

${ }^{\mathrm{b}}$ Values were reverse score square-root transformed prior to analysis.

previous studies using similar covariates $(p r=.34$, Grisham \& Williams, 2009; $p r=$ .12, Shaw et al., 2017). Exploratory analyses show that the RTS was associated with the ordering and mental neutralizing subscales, but not the other subscales of the questionnaire measure of OC symptom severity when controlling for depressive and anxiety symptom severity. The RTS did not retain an association with the interview measure of OC symptom severity when controlling for depressive and anxiety symptom severity, and thus Hypothesis $2 \mathrm{~b}$ was not supported. Similarly, exploratory analyses show that when depressive and anxiety symptom severity were controlled for, the RTS was not associated with either subscale of the interview measure of OC symptom severity.

If future studies can replicate the results for Hypothesis $2 \mathrm{a}$, this would be consistent with the idea that an RTS and OC symptom severity are related independent of both 
Table 4 Exploratory analyses of the RTS and depressive and anxiety symptom severity predicting the OC symptom severity interview measure subscales, controlling for subsamples

\begin{tabular}{|c|c|c|c|c|c|c|c|c|c|c|}
\hline \multirow[t]{2}{*}{ Variable } & \multicolumn{5}{|c|}{ Model 1} & \multicolumn{5}{|c|}{ Model 2} \\
\hline & $B$ & $S E B$ & $\beta$ & $p r$ & $p$ & $B$ & $S E B$ & $\beta$ & $p r$ & $p$ \\
\hline \multicolumn{11}{|c|}{ Predicting Y-BOCS obsessions } \\
\hline RRS brooding & 0.32 & 0.11 & 0.31 & .29 & .005 & 0.15 & 0.12 & 0.15 & .13 & .217 \\
\hline $\mathrm{BDI}^{\mathrm{a}}$ & & & & & & 0.22 & 0.37 & 0.08 & .06 & .566 \\
\hline $\mathrm{BAI}^{\mathrm{a}}$ & & & & & & 0.51 & 0.29 & 0.22 & .19 & .086 \\
\hline \multicolumn{11}{|c|}{ Predicting Y-BOCS compulsions } \\
\hline RRS brooding & 0.21 & 0.11 & 0.19 & .19 & .074 & 0.09 & 0.13 & 0.09 & .08 & .477 \\
\hline $\mathrm{BDI}^{\mathrm{a}}$ & & & & & & 0.55 & 0.39 & 0.19 & .15 & .166 \\
\hline $\mathrm{BAI}^{\mathrm{a}}$ & & & & & & -0.08 & 0.31 & -0.03 & -.03 & .787 \\
\hline
\end{tabular}

Note: $n=93$ for Model 1 (regression model including subsamples and RRS brooding) and $n=89$ for Model 2 (regression model including subsamples, RRS brooding, BDI, and BAI). BAI, Beck Anxiety Inventory; BDI, Beck Depression Inventory; $O C$, obsessive-compulsive; $p r$, partial correlation coefficient; RRS brooding, brooding subscale of the Ruminative Response Scale; $R T S$, ruminative thinking style; $Y$-BOCS, Yale-Brown Obsessive-Compulsive Scale.

a Values were square-root transformed prior to analysis.

variables' associations with depressive and anxiety severity. The relation between an RTS and OC symptom severity could be explained by an RTS facilitating dysfunctional appraisals of intrusive thoughts (Raines et al., 2017; Wahl et al., 2019). For instance, thinking about one's obsessions with an RTS (e.g., "why do I, of all people, experience these impulses to stab someone?") may facilitate misinterpretations of these obsessions as disclosing some hidden personal characteristic (e.g., "These impulses must mean that I am a dangerous person"). Such dysfunctional interpretations are a presumed key factor in the development and maintenance of OC symptoms (Rachman, 1998). Alternatively, ruminating on intrusive thoughts might increase the accessibility of these thoughts and thus lead individuals to experience intrusive thoughts more frequently (Grisham \& Williams, 2009). Further studies with experimental or prospective designs could allow a closer examination of the underlying mechanisms of how an RTS may affect OC symptoms and vice versa. Ultimately, current cognitive-behavioral models of OCD (e.g., Salkovskis, 1985) may need to be extended by including the role of an RTS in the maintenance of OCD.

Depending on future studies, it might be advisable to include supplemental interventions that directly target an RTS in OCD treatment. Our preliminary exploratory analyses suggest that such interventions may be especially warranted for individuals predominantly experiencing ordering and mental neutralizing symptoms, but further replications are needed. Specific supplemental interventions could include adapted versions of RFCBT that aim, among other things, to interrupt the habitual use of an RTS (Watkins, 2016); mindfulness-based cognitive therapy that increases a nonjudgmental, accepting attitude toward OC symptoms (Külz et al., 2019); or interpretative bias modification that aims to modify the interpretation of potentially ambiguous situations that can be common starting points for excessive ruminative thinking patterns (Hirsch et al., 2020). For example, some of the components of RFCBT could be applied to an RTS in individuals diagnosed with OCD 
without any or with only small changes. Using functional analysis and self-monitoring, individuals with OCD could learn to identify situations that result in a strong tendency to adopt an RTS. However, other components of RFCBT might have to be tailored to individuals with OCD: While individuals diagnosed with depression might subsequently work on finding alternative, more helpful behaviors or thoughts to replace an RTS, in individuals with OCD, exposure to the original obsessions would have to be considered as a further, potentially more adaptive alternative.

However, if future studies replicate our results for Hypothesis $2 \mathrm{~b}$ and fail to demonstrate associations between an RTS and OC symptom severity when controlling for depressive and anxiety symptom severity, it seems likely that the high comorbidity of depression and/or anxiety disorders with OCD (Baer et al., 2017; Lieb et al., 2019) is the main reason that an RTS and OC symptom severity are associated. This high comorbidity reflects the positive associations of OC symptom severity with both depressive and anxiety symptom severity (e.g., Clark et al., 2005; Tellawi et al., 2016). At the same time, the latter two constructs are also positively associated with an RTS (e.g., Merino et al., 2016; Treynor et al., 2003). Thus, depressive and anxiety symptom severity could potentially act as confounders that lead to the association between an RTS and OC symptom severity.

The different findings for the two measures of OC symptom severity might be explained in various ways. First, they might be due to the questionnaire (OCI-R) assessing different aspects of OC symptom severity than the interview (Y-BOCS). The OCI-R assesses only the distress associated with symptoms of OCD, whereas the Y-BOCS measures more global OC symptom severity including the time spent on, interference from, distress of, resistance against, and control over OC symptoms (Abramowitz \& Deacon, 2006). Consistent with this idea, previous studies show associations between the OCI-R and Y-BOCS (e.g., $r=.41$, Abramowitz \& Deacon, 2006; $r=.45$, Deacon \& Abramowitz, 2005; $r=.43$, Gönner et al., 2008) that stay below what might be considered good convergent validity in this context (McGuire et al., 2017). It is possible that an RTS is particularly associated with the distress caused by some OC symptoms but no other aspects such as how time-consuming OC symptoms are. This may also explain why after controlling for depressive and anxiety symptom severity, Grisham and Williams (2009) reported an association of an RTS with the OCI-R while Shaw et al. (2017) did not find an RTS to be related to the overall score of the Dimensional Obsessive-Compulsive Scale (DOCS; Abramowitz et al., 2010). Similar to the Y-BOCS, the DOCS assesses OC symptom severity more globally. Alternatively, the variance of the OCI-R explained by the RTS could have been at least partly caused by common method variance (e.g., Podsakoff et al., 2003) because these variables were both measured using questionnaires, whereas the Y-BOCS is an interview measure. Future studies should investigate whether these associations are retained when OC symptom severity is assessed using different measures. For instance, comparing the association of an RTS with scores on the DOCS to associations of an RTS with scores on the OCI-R and Y-BOCS may illuminate possible reasons for the differing results in our study further.

Limitations of the present study include the fact that our sample for analyzing the association of an RTS with the interview measure of OC symptom severity was relatively small, which may have limited our power to detect small to medium associations. Furthermore, on average, participants in our study had lower comorbidities (Baer et al., 2017; Quarantini et al., 2011; Torres et al., 2006) and lower scores on the measure of depressive symptom severity (cf. Clayton et al., 1999; MacDonald et al., 1999) than have previously been reported for other OCD samples. This means that our study's results may 
not be transferable to those of other samples of individuals diagnosed with OCD. Future studies should investigate whether our results can be replicated with different and larger samples of individuals diagnosed with OCD.

To conclude, our study revealed that in individuals diagnosed with OCD, an RTS was associated with a questionnaire-based but not an interview-based measure of OC symptom severity after controlling for depressive and anxiety symptom severity. Further studies should investigate more closely the nature of the relationship of an RTS with the distress associated with OC symptoms and also target the diverging results of the questionnaire and the interview measure of OC symptom severity. Ultimately, psychological treatments of OCD may be supplemented by interventions that specifically target an RTS, as RFCBT (Watkins, 2016) does in the context of major depressive disorder.

Supplementary Information The online version contains supplementary material available at https:/doi.org/ 10.1007/s41811-021-00112-y.

Acknowledgements The authors would like to thank Andrea H. Meyer for his assistance in preparing the manuscript.

Funding Open Access funding provided by Universität Basel (Universitätsbibliothek Basel). This research did not receive any specific grant from funding agencies in the public, commercial, or not-for-profit sectors. The Swiss National Science Foundation (SNSF) is funding the first author's PhD position. The SNSF was not involved in the research or manuscript preparation.

\section{Declarations}

Conflict of Interest The authors declare no competing interests.

Supplementary Information The online version contains supplementary material available at https://doi.org/ 10.1007/s41811-021-00112-y.

Open Access This article is licensed under a Creative Commons Attribution 4.0 International License, which permits use, sharing, adaptation, distribution and reproduction in any medium or format, as long as you give appropriate credit to the original author(s) and the source, provide a link to the Creative Commons licence, and indicate if changes were made. The images or other third party material in this article are included in the article's Creative Commons licence, unless indicated otherwise in a credit line to the material. If material is not included in the article's Creative Commons licence and your intended use is not permitted by statutory regulation or exceeds the permitted use, you will need to obtain permission directly from the copyright holder. To view a copy of this licence, visit http://creativecommons.org/licenses/by/4.0/.

\section{References}

Abramowitz, J. S., \& Deacon, B. J. (2006). Psychometric properties and construct validity of the obsessivecompulsive inventory-revised: Replication and extension with a clinical sample. Journal of Anxiety Disorders, 20(8), 1016-1035. https://doi.org/10.1016/j.janxdis.2006.03.001.

Abramowitz, J. S., Deacon, B. J., Olatunji, B. O., Wheaton, M. G., Berman, N. C., Losardo, D., Timpano, K. R., McGrath, P. B., Riemann, B. C., Adams, T., Bjorgvinsson, T., Storch, E. A., \& Hale, L. R. (2010). Assessment of obsessive-compulsive symptom dimensions: Development and evaluation of the dimensional obsessivecompulsive scale. Psychological Assessment, 22(1), 180-198. https://doi.org/10.1037/a0018260. 
American Psychiatric Association. (1994). Diagnostic and statistical manual of mental disorders (4th ed.). American Psychiatric Association. (2013). Diagnostic and statistical manual of mental disorders (5th ed.).

Armstrong, T., Zald, D. H., \& Olatunji, B. O. (2011). Attentional control in OCD and GAD: Specificity and associations with core cognitive symptoms. Behaviour Research and Therapy, 49(11), 756-762. https:// doi.org/10.1016/j.brat.2011.08.003.

Baer, L., Fang, A., Berman, N. C., \& Minichiello, W. E. (2017). Mood and anxiety disorder comorbidity in OCD. In C. Pittenger (Ed.), Obsessive-compulsive disorder: Phenomenology, pathophysiology, and treatment (pp. 603611). Oxford University Press.

Beck, A. T., Erbaugh, J., Ward, C. H., Mock, J., \& Mendelsohn, M. (1961). An inventory for measuring depression. Archives of General Psychiatry, 4(6), 561-571.

Beck, A. T., Brown, G., Epstein, N., \& Steer, R. A. (1988a). An inventory for measuring clinical anxietyPsychometric properties. Journal of Consulting and Clinical Psychology, 56(6), 893-897. https://doi.org/ 10.1037/0022-006x.56.6.893.

Beck, A. T., Steer, R. A., \& Garbin, M. G. (1988b). Psychometric properties of the Beck depression inventory-25 years of evaluation. Clinical Psychology Review, 8(1), 77-100. https://doi.org/10.1016/ 0272-7358(88)90050-5.

Clark, D. A., Antony, M. M., Beck, A. T., Swinson, R. P., \& Steer, R. A. (2005). Screening for obsessive and compulsive symptoms: Validation of the Clark-Beck obsessive-compulsive inventory. Psychological Assessment, 17(2), 132-143. https://doi.org/10.1037/1040-3590.17.2.132.

Clayton, I. C., Richards, J. C., \& Edwards, C. J. (1999). Selective attention in obsessive-compulsive disorder. Journal of Abnormal Psychology, 108(1), 171-175. https://doi.org/10.1037/0021-843X.108.1. 17110067003.

Dar, K. A., \& Iqbal, N. (2015). Worry and rumination in generalized anxiety disorder and obsessive compulsive disorder. Journal of Psychology, 149(8), 866-880. https://doi.org/10.1080/00223980.2014. 986430.

Deacon, B. J., \& Abramowitz, J. S. (2005). The Yale-Brown obsessive compulsive scale: Factor analysis, construct validity, and suggestions for refinement. Journal of Anxiety Disorders, 19(5), 573-585. https:// doi.org/10.1016/j.janxdis.2004.04.009.

Ehring, T., \& Watkins, E. R. (2008). Repetitive negative thinking as a transdiagnostic process. International Journal of Cognitive Therapy, 1(3), 192-205. https://doi.org/10.1680/ijct.2008.1.3.192.

Foa, E. B., Huppert, J. D., Leiberg, S., Langner, R., Kichic, R., Hajcak, G., \& Salkovskis, P. M. (2002). The obsessive-compulsive inventory: Development and validation of a short version. Psychological Assessment, 14(4), 485-496. https://doi.org/10.1037//1040-3590.14.4.485.

Fontenelle, L. F., Mendlowicz, M. V., \& Versiani, M. (2006). The descriptive epidemiology of obsessivecompulsive disorder. Progress in Neuro-Psychopharmacology \& Biological Psychiatry, 30(3), 327-337. https://doi.org/10.1016/j.pnpbp.2005.11.001.

Goodman, W. K., Price, L. H., Rasmussen, S. A., Mazure, C., Delgado, P., Heninger, G. R., \& Charney, D. S. (1989a). The Yale-Brown obsessive compulsive scale II. Validity. Archives of General Psychiatry, 46(11), 1012-1016.

Goodman, W. K., Price, L. H., Rasmussen, S. A., Mazure, C., Fleischmann, R. L., Hill, C. L., Heninger, G. R., \& Charney, D. S. (1989b). The Yale-Brown obsessive compulsive scale. I. Development, use, and reliability. Archives of General Psychiatry, 46(11), 1006-1011 https://www.ncbi.nlm.nih.gov/pubmed/ 2684084.

Gönner, S., Leonhart, R., \& Ecker, W. (2008). The Obsessive-Compulsive Inventory-Revised (OCI-R): Validation of the German version in a sample of patients with OCD, anxiety disorders, and depressive disorders. Journal of Anxiety Disorders, 22(4), 734-749.

Grabill, K., Merlo, L., Duke, D., Harford, K. L., Keeley, M. L., Geffken, G. R., \& Storch, E. A. (2008). Assessment of obsessive-compulsive disorder: A review. Journal of Anxiety Disorders, 22(1), 1-17. https://doi.org/10.1016/j.janxdis.2007.01.012.

Grisham, J. R., \& Williams, A. D. (2009). Cognitive control of obsessional thoughts. Behaviour Research and Therapy, 47(5), 395-402. https://doi.org/10.1016/j.brat.2009.01.014.

Guzick, A. G., Reid, A. M., Balki, A. M., Flores, C., Hancock-Smith, A. D., Olsen, B., Muller, G., Geffken, G. R., \& McNamara, J. P. H. (2017). Diagnostic description and prevalence. In J. S. Abramowitz, D. McKay, \& E. A. Storch (Eds.), The Wiley handbook of obsessive compulsive disorders (Vol. 1, pp. 24 43). Wiley.

Hand, I., \& Büttner-Westphal, H. (1991). Die Yale-Brown Obsessive Compulsive Scale (Y-BOCS): Ein halbstrukturiertes interview zur beurteilung des schweregrades von denk- und handlungszwängen. Verhaltenstherapie, 1(3), 223-225. 
Hautzinger, M., Bailer, M., Worall, H., \& Keller, F. (1995). Beck-Depressions-Inventar (BDI) [Beck Depression Inventory (BDI)] (2nd rev. ed.). Huber.

Hirsch, C. R., Krahé, C., Whyte, J., Bridge, L., Loizou, S., Norton, S., \& Mathews, A. (2020). Effects of modifying interpretation bias on transdiagnostic repetitive negative thinking. Journal of Consulting and Clinical Psychology, 88(3), 226-239. https://doi.org/10.1037/ccp0000455.

Huffziger, S., \& Kühner, C. (2012). Die ruminationsfacetten brooding und reflection. Zeitschrift für klinische psychologie und psychotherapie, 41(1), 38-46.

Jacobsen, D., Kloss, M., Fricke, S., Hand, I., \& Moritz, S. (2003). Reliabilität der deutschen Version der YaleBrown Obsessive Compulsive Scale. Verhaltenstherapie, 13(2),111-113.

Jungmann, S. M., Vollmer, N., Selby, E. A., \& Witthoft, M. (2016). Understanding dysregulated behaviors and compulsions: An extension of the emotional cascade model and the mediating role of intrusive thoughts. Frontiers in Psychology, 7. https://doi.org/10.3389/fpsyg.2016.00994.

Kline, R. B. (2016). Principles and practice of structural equation modeling (4th ed.). The Guilford Press.

Koch, J., \& Exner, C. (2015). Selective attention deficits in obsessive-compulsive disorder: The role of metacognitive processes. Psychiatry Research, 225(3), 550-555. https://doi.org/10.1016/j.psychres.2014. 11.049 .

Kollárik, M., Heinzel, C. V., Hofer, P., Lieb, R., \& Wahl, K. (2020). Effects of rumination on unwanted intrusive thoughts: A replication and extension. Journal of Experimental Psychopathology, 1-16. https:// doi.org/10.1177/2043808720912583.

Külz, A. K., Landmann, S., Cludius, B., Rose, N., Heidenreich, T., Jelinek, L., Alsleben, H., Wahl, K., Philipsen, A., Voderholzer, U., Maier, J. G., \& Moritz, S. (2019). Mindfulness-based cognitive therapy (MBCT) in patients with obsessive-compulsive disorder (OCD) and residual symptoms after cognitive behavioral therapy (CBT): A randomized controlled trial. European Archives of Psychiatry and Clinical Neuroscience, 269(2), 223-233. https://doi.org/10.1007/s00406-018-0957-4.

Lieb, R., Hofer, P., \& Wahl, K. (2019). Epidemiology of obsessive-compulsive disorder. In L. Fontenelle \& M. Yücel (Eds.), A transdiagnostic approach to obsessions, compulsions and related phenomena (pp. 113-127). Cambridge University Press. https://doi.org/10.1017/9781108164313.011.

MacDonald, P. A., Antony, M. M., MacLeod, C. M., \& Swinson, R. P. (1999). Negative priming for obsessive-compulsive checkers and noncheckers [Peer Reviewed]. Journal of Abnormal Psychology, 108(4). https://doi.org/10.1037/0021-843X.108.4.67910609432.

Margraf, J., \& Ehlers, A. (2007). Beck Angst-Inventar (BAI)-Manual [Beck Anxiety Inventory (BAI)Manual]. Harcourt Test Services.

McGuire, J. F., Storch, E. A., \& Goodman, W. (2017). Clinical rating scales for OCD. In C. Pittenger (Ed.), Obsessive-compulsive disorder: Phenomenology, pathophysiology, and treatment (pp. 137-148). Oxford University Press.

Merino, H., Ferreiro, F., \& Senra, C. (2014). Cognitive vulnerability to emotional symptoms: Reconsidering the role of worry and rumination. Journal of Psychopathology and Behavioral Assessment, 36(1), 136142. https://doi.org/10.1007/s10862-013-9374-1.

Merino, H., Senra, C., \& Ferreiro, F. (2016). Are worry and rumination specific pathways linking neuroticism and symptoms of anxiety and depression in patients with generalized anxiety disorder, major depressive disorder and mixed anxiety-depressive disorder? PLoS One, 11(5). https://doi.org/10.1371/journal.pone. 0156169 .

Nolen-Hoeksema, S. (2000). The role of rumination in depressive disorders and mixed anxiety/depressive symptoms. Journal of Abnormal Psychology, 109(3), 504-511. https://doi.org/10.1037//0021-843x.109. 3.504 .

Nolen-Hoeksema, S., \& Morrow, J. (1991). A prospective-study of depression and posttraumatic stress symptoms after a natural disaster - the 1989 Loma-Prieta Earthquake. Journal of Personality and Social Psychology, 61(1), 115-121. https://doi.org/10.1037/0022-3514.61.1.115.

Nolen-Hoeksema, S., Wisco, B. E., \& Lyubomirsky, S. (2008). Rethinking rumination. Perspectives on Psychological Science, 3(5), 400-424. https://doi.org/10.1111/j.1745-6924.2008.00088.x.

Podsakoff, P. M., MacKenzie, S. B., Lee, J. Y., \& Podsakoff, N. P. (2003). Common method biases in behavioral research: A critical review of the literature and recommended remedies. Journal of Applied Psychology, 88(5), 879-903. https://doi.org/10.1037/0021-9101.88.5.879.

Quarantini, L. C., Torres, A. R., Sampaio, A. S., Fossaluza, V., de Mathis, M. A., do Rosario, M. C., Fontenelle, L. F., Ferrao, Y. A., Cordioli, A. V., Petribu, K., Hounie, A. G., Miguel, E. C., Shavitt, R. G., \& Koenen, K. C. (2011). Comorbid major depression in obsessive-compulsive disorder patients. Comprehensive Psychiatry, 52(4), 386-393. https://doi.org/10.1016/j.comppsych.2010.09.006.

Rachman, S. (1998). A cognitive theory of obsessions: Elaborations. Behaviour Research and Therapy, 36(4), 385-401. https://doi.org/10.1016/S0005-7967(97)10041-9. 
Raines, A. M., Vidaurri, D. N., Portero, A. K., \& Schmidt, N. B. (2017). Associations between rumination and obsessive-compulsive symptom dimensions. Personality and Individual Differences, 113, 63-67. https:// doi.org/10.1016/j.paid.2017.03.001.

Rees, C. S., Roberts, L. D., van Oppen, P., Eikelenboom, M., Hendriks, A. A. J., van Balkom, A. J. L. M., \& van Megen, H. (2014). Personality and symptom severity in obsessive-compulsive disorder: The mediating role of depression. Personality and Individual Differences, 71, 92-97. https://doi.org/10.1016/j.paid. 2014.07.025.

Rogers, A. H., Bakhshaie, J., Ditre, J. W., Manning, K., Mayorga, N. A., Viana, A. G., \& Zvolensky, M. J. (2019). Worry and rumination: Explanatory roles in the relation between pain and anxiety and depressive symptoms among college students with pain. Journal of American College Health, 67(3), 275-282. https://doi.org/10.1080/07448481.2018.1481071.

Salkovskis, P. M. (1985). Obsessional-compulsive problems - A cognitive-behavioral analysis. Behaviour Research and Therapy, 23(5), 571-583. https://doi.org/10.1016/0005-7967(85)90105-6.

Shaw, A. M., Carbonella, J. Y., Hall, K. A. A., \& Timpano, K. R. (2017). Obsessive-compulsive and depressive symptoms: The role of depressive cognitive styles. Journal of Psychology, 151(6), 532-546. https://doi.org/10.1080/00223980.2017.1372341.

Tellawi, G., Williams, M. T., \& Chasson, G. S. (2016). Interpersonal hostility and suspicious thinking in obsessive-compulsive disorder. Psychiatry Research, 243, 295-302. https://doi.org/10.1016/j.psychres. 2016.06.038.

Torres, A. R., Prince, M. J., Bebbington, P. E., Bhugra, D., Brugha, T. S., Farrell, M., Jenkins, R., Lewis, G., Meltzer, H., \& Singleton, N. (2006). Obsessive-compulsive disorder: Prevalence, comorbidity, impact, and help-seeking in the British National Psychiatric Morbidity Survey of 2000. American Journal of Psychiatry, 163(11), 1978-1985. https://doi.org/10.1176/appi.ajp.163.11.1978.

Treynor, W., Gonzalez, R., \& Nolen-Hoeksema, S. (2003). Rumination reconsidered: A psychometric analysis. Cognitive Therapy and Research, 27(3), 247-259. https://oi.org/10.1023/A:1023910315561.

Wahl, K., Ertle, A., Bohne, A., Zurowski, B., \& Kordon, A. (2011). Relations between a ruminative thinking style and obsessive-compulsive symptoms in non-clinical samples. Anxiety, Stress, and Coping, 24(2), 217-225. https://doi.org/10.1080/10615806.2010.482985.

Wahl, K., van den Hout, M., \& Lieb, R. (2019). Rumination on unwanted intrusive thoughts affects the urge to neutralize in nonclinical individuals. Journal of Obsessive-Compulsive and Related Disorders, 20, 4-12. https://doi.org/10.1016/j.jocrd.2018.02.002.

Wahl, K., van den Hout, M., Heinzel, C. V., Kollárik, M., Meyer, A., Benoy, C., Berberich, G., Domschke, K., Gloster, A., Gradwohl, G., Hofecker, M., Jähne, A., Koch, S., Külz, A. K., Moggi, F., Poppe, C., Riedel, A., Rufer, M., Stierle, C., et al. (in press). Rumination about obsessive symptoms and mood maintains obsessive-compulsive symptoms and depressed mood: An experimental study. Journal of Abnormal Psychology.

Watkins, E. R. (2016). Rumination-focused cognitive-behavioral therapy for depression. The Guilford Press.

Wei, M. A., Van Kirk, N., Reid, A. M., Garner, L. E., Krompinger, J. W., Crosby, J. M., Elias, J. A., \& Weisz, J. R. (2020). Emotion regulation strategy use and symptom change during intensive treatment of transitional age youth patients with obsessive compulsive disorder. Journal of Behavioral and Cognitive Therapy, 30, 95-102. https://doi.org/10.1016/j.jbct.2020.03.009.

Wittchen, H. U., Wunderlich, U., Gruschwitz, S., \& Zaudig, M. (1997). SKID-I. Strukturiertes klinisches interview für DSM-IV achse I: Psychische störungen. interviewheft und beurteilungsheft. Eine deutschsprachige, erweiterte bearbeitung der amerikanischen originalversion des SCID-I [SCID-I. Structured clinical interview for DSM-IV Axis I: mental disorders. Booklet for interview and assessment. A German, extended edition of the American original version of the SCID-I]. Hogrefe

Woody, S. R., Steketee, G., \& Chambless, D. L. (1995). Reliability and validity of the Yale-Brown obsessivecompulsive scale. Behaviour Research and Therapy, 33(5), 597-605. https://doi.org/10.1016/00057967(94)00076-V.

Yang, M. J., Kim, B. N., Lee, E. H., Lee, D., Yu, B. H., Jeon, H. J., \& Kim, J. H. (2014). Diagnostic utility of worry and rumination: A comparison between generalized anxiety disorder and major depressive disorder. Psychiatry and Clinical Neurosciences, 68(9), 712-720. https://doi.org/10.1111/pcn.12193.

Publisher's Note Springer Nature remains neutral with regard to jurisdictional claims in published maps and institutional affiliations. 


\section{Affiliations}

\section{Carlotta V. Heinzel ${ }^{1}$ - Martin Kollárik ${ }^{1}$ - Marcel Miché ${ }^{1}$ - Annika Clamor $^{2}$. Andrea Ertle ${ }^{3} \cdot$ Roselind Lieb ${ }^{1} \cdot$ Karina Wahl ${ }^{1}$}

Carlotta V. Heinzel

carlotta.heinzel@unibas.ch

Martin Kollárik

martin.kollarik@unibas.ch

Marcel Miché

marcel.miche@unibas.ch

Annika Clamor

annika.clamor@uni-hamburg.de

Andrea Ertle

andrea.ertle@hu-berlin.de

Roselind Lieb

roselind.lieb@unibas.ch

1 Division of Clinical Psychology and Epidemiology, Department of Psychology, University of Basel, Missionsstr. 62a, 4055 Basel, Switzerland

2 Clinical Psychology and Psychotherapy, Institute of Psychology, Faculty of Psychology and Human Movement Sciences, Universität Hamburg, Hamburg, Germany

3 Institute of Psychology, Humboldt-Universität zu Berlin, Berlin, Germany 